\title{
Accessibility challenges of e-commerce websites
}

\author{
Patricia Acosta-Vargas ${ }^{\text {Corresp., } 1}$, Belén Salvador-Acosta ${ }^{2}$, Luis Salvador-Ullauri ${ }^{3}$, Janio Jadán-Guerrero ${ }^{4}$ \\ ${ }^{1}$ Intelligent and Interactive Systems Laboratory/FICA/Industrial Engineering, Universidad de Las Américas - Ecuador, Quito, Ecuador \\ 2 Facultad de Medicina, Universidad de Las Américas-Ecuador, Quito, Ecuador \\ 3 Department of Software and Computing Systems, University of Alicante, Alicante, Alicante, España \\ ${ }^{4}$ Centro de Investigación en Mecatrónica y Sistemas Interactivos - MIST, Universidad Tecnológica Indoamérica, Quito, Ecuador \\ Corresponding Author: Patricia Acosta-Vargas \\ Email address: patricia.acosta@udla.edu.ec
}

Today, there are many e-commerce websites, but not all of them are accessible.

Accessibility is a crucial element that can make a difference and determine the success or failure of a digital business. The study was applied to 50 e-commerce sites in the top rankings according to the classification proposed by ecommerceDB. In evaluating the web accessibility of e-commerce sites, we applied an automatic review method based on a modification of Website Accessibility Conformance Evaluation Methodology (WCAG-EM) 1.0. To evaluate accessibility, we used Web Accessibility Evaluation Tool (WAVE) with the extension for Google Chrome, which helps verify password-protected, locally stored, or highly dynamic pages. The study found that the correlation between the ranking of ecommerce websites and accessibility barriers is 0.329 , indicating that the correlation is low positive according to Spearman's Rho. According to the WAVE analysis, the research results reveal that the top ten most accessible websites are Sainsbury's Supermarkets, Walmart, Target Corporation, Macy's, IKEA, H \& M Hennes, Chewy, The Kroger, QVC, and Nike. The most significant number of accessibility barriers relate to contrast errors that must be corrected for e-commerce websites to reach an acceptable level of accessibility. The most neglected accessibility principle is perceivable, representing $83.1 \%$, followed by operable with $13.7 \%$, in third place is robust with $1.7 \%$ and finally understandable with $1.5 \%$. Future work suggests constructing a software tool that includes artificial intelligence algorithms that help the software identify accessibility barriers. 


\section{Accessibility challenges of e-commerce websites}

2 Patricia Acosta-Vargas ${ }^{1}$, Belén Salvador-Acosta ${ }^{2}$, Luis Salvador-Ullauri ${ }^{3}$, Janio

3 Jadán-Guerrero ${ }^{4}$

$4 \quad{ }^{1}$ Intelligent and Interactive Systems Laboratory, Universidad de Las Américas, Quito 170125,

5 Ecuador

$6 \quad{ }^{2}$ Facultad de Medicina, Universidad de Las Américas, Quito 170125, Ecuador.

$7 \quad{ }^{3}$ Department of Software and Computing Systems, University of Alicante, 03690 Alicante,

8 Spain

$9 \quad{ }^{4}$ Centro de Investigación en Mecatrónica y Sistemas Interactivos - MIST, Universidad

10 Tecnológica Indoamérica, Quito, Ecuador

11 Corresponding Author:

12 Patricia Acosta-Vargas ${ }^{1}$

13 Redondel del Ciclista-Antigua Vía a Nayón, Quito, Pichincha, EC 170124, Ecuador

Email address: patricia.acosta@udla.edu.ec

\section{Abstract}

Today, there are many e-commerce websites, but not all of them are accessible. Accessibility is a crucial element that can make a difference and determine the success or failure of a digital business. The study was applied to 50 e-commerce sites in the top rankings according to the classification proposed by ecommerceDB.

In evaluating the web accessibility of e-commerce sites, we applied an automatic review method based on a modification of Website Accessibility Conformance Evaluation Methodology (WCAGEM) 1.0. To evaluate accessibility, we used Web Accessibility Evaluation Tool (WAVE) with the extension for Google Chrome, which helps verify password-protected, locally stored, or highly dynamic pages.

The study found that the correlation between the ranking of e-commerce websites and accessibility barriers is 0.329 , indicating that the correlation is low positive according to Spearman's Rho.

According to the WAVE analysis, the research results reveal that the top ten most accessible websites are Sainsbury's Supermarkets, Walmart, Target Corporation, Macy's, IKEA, H \& M Hennes, Chewy, The Kroger, QVC, and Nike. The most significant number of accessibility barriers relate to contrast errors that must be corrected for e-commerce websites to reach an acceptable level of accessibility. The most neglected accessibility principle is perceivable, representing $83.1 \%$, followed by operable with $13.7 \%$, in third place is robust with $1.7 \%$ and finally understandable with $1.5 \%$. Future work suggests constructing a software tool that includes artificial intelligence algorithms that help the software identify accessibility barriers.

\section{Introduction}

Internet technology has radically revolutionized the world of communications to become a global means of communication. The number of e-commerce websites has increased significantly due to the pandemic COVID-19 (World Health Organization (WHO), 2021b); the global confinement caused many businesses to close.

Statistics from the Statista website (Statista, 2021) indicate that e-commerce has undergone a substantial transformation in recent years thanks to digitization in modern life. 
43 However, for Statista (Statista, 2020), e-commerce websites have seen a notable increase in 44 worldwide traffic flow between January 2019 and June 2020. By 2022, more than 2.14 billion 45 people worldwide are forecast to shop online, and global e-commerce revenues could grow to $\$ 5.4$ 46 trillion (Statista, 2021).

47 Figure 1 shows the search of terms performed in the last five years in Google Trends (Google, 48 2021) related to accessibility, e-commerce, and Web Content Accessibility Guidelines (WCAG) 49 (World Wide Web Consortium, 2018). We observe that the term e-commerce tends to grow from 50 March 2020 during the COVID-19 where most users began to consume massively digital material 51 and are oriented to use e-commerce applications, to reduce the number of infections, we also 52 observe that the term accessibility and WCAG tend to grow.

53

54 55 56

57 58 59 60
Figure 1 The trend in Google Trends for terms related to accessibility, e-commerce, and WCAG. Diagram of the trend of the terms in the last five years worldwide.

E-commerce websites have grown considerably, but most of them are not accessible. Accessibility (Patricia Acosta-Vargas et al., 2018) refers to a set of techniques, guidelines or methods that make web content and functionality compatible with the needs of all people regardless of their physical or technological capabilities.

Statements from the World Health Organization (World Health Organization (WHO), 2017) reveal that $15 \%$ of the world's population suffers from some disability. Therefore, it is essential to apply web accessibility guidelines to e-commerce sites. A well-designed website can be easy to navigate for web users (World Wide Web Consortium, 2018). Accessibility also benefits several users (Andersen et al., 2020) with aging-related difficulties that decrease their visual ability due to presbyopia.

WCAG 2.1 (World Wide Web Consortium, 2018) proposes applying accessibility principles to reduce accessibility barriers perceived by users when interrelating with a website.

The outcomes of this investigation evidenced that $25.6 \%$ of the e-commerce websites in the sample present images that require the inclusion of alternative text; additionally, we found that $54.4 \%$ of the sites present contrast problems related to the principle of perception.

As future work, we suggest considering the problems of hardware limitations and interstitial advertising. We also recommend building a software tool with artificial intelligence algorithms that include new heuristics to help developers identify accessibility barriers to generate more accessible and inclusive sites.

The remainder of this paper is structured as follows; Section II reviews the literature on web accessibility. Section III shows the methodology used to evaluate accessibility in e-commerce sites. Section IV shows the results obtained by applying the evaluation. Section V contains the discussion of the outcomes. Section VI explains the restrictions of the research. Finally, conclusions and future work are described in parts VII and VIII.

Peer] Comput. Sci. reviewing PDF | (CS-2021:09:65405:3:0:NEW 23 Jan 2022) 


\section{Literature review}

84 The pandemic status related to COVID-19 has accelerated the movement of industry, education

85

86

87

88

89

90

91

92

93

94

95

96

97

98

99

100

101

102

103

104

105

106

107

108

109

110

111

112

113

114

115

116

117

118

119

120

121

122

and business to the virtual world, and on par with these events, several e-commerce websites have been created (Munkova et al., 2021).

According to (Villa \& Monzón, 2021), (Pollák et al., 2021) and (Paștiu et al., 2020), COVID-19 has impacted the growth of e-commerce websites; unprecedented worldwide changes are evident in the various forms of consumer habits. Consumer behavior shows an evolutionary shift from offline to online, where e-commerce applications require 1) more accessible designs, 2) greater sustainability, 3) software applications that utilize business intelligence.

In reviewing the literature, we found some research related to the evaluation of web accessibility in e-commerce sites, methods, and tools used in automatic inspection. The study (Paz et al., 2021) argues the accessibility with which software products, including e-commerce stores, should be designed. It indicates that some countries apply laws and government policies that ensure accessibility to websites considering different skills and abilities. The study compared the results of five tools for inspecting the accessibility of e-commerce websites; the conclusions show that there are no $100 \%$ accessible sites.

The research $(\mathrm{Xu}, 2020)$ compares the accessibility of e-commerce, considering compliance with web accessibility guidelines. As a case study, they applied the evaluation to 45 e-commerce websites. They used the Web Accessibility Assessment Tool (WAVE); the results revealed that websites with Accessible Rich Internet Applications (ARIA) attribute lower accessibility levels overall. They concluded that the accessibility of mature websites was higher than that of new websites with innovative products.

The study (Alshamari, 2016) argues that many tools can help make a website accessible. The article explores some available tools that help designers and developers evaluate web accessibility. The research results indicate that navigation, readability, and timing are the most common accessibility issues when evaluating the accessibility of selected websites.

The article (Padure \& Pribeanu, 2020) argues that WAVE tool is a free tool provided by Web Accessibility In Mind (WebAIM). The authors indicate that WAVE offers a color-coding system: red for errors that need to be corrected urgently, green for correct lines but still need to be checked, and yellow for potential problems that need manual review.

The study's authors (Oliveira et al., 2020) infer that accessibility is fundamental in the democratization of technologies, so applying the Web Content Accessibility Guidelines (WCAG 2.1 ) is essential. The accessibility evaluation was applied to three websites operating in Portugal, considering the three best-positioned retailers' ranking corresponding to the SimilarWeb. The results obtained established a collection of suggestions to increase the accessibility of websites aimed at e-commerce. Our study differs from (Oliveira et al., 2020) and the research (Xu, 2020) because the total sample is taken from ecommerceDB, which presents the e-commerce websites related to market trends and a ranking of the leading e-commerce stores. Our evaluation applied a new method based on the methodology (WCAG-EM) 1.0. In addition, the WAVE evaluation tool is based on version 3.1.6, updated as of October 14, 2021, which includes the plugin component

Peer] Comput. Sci. reviewing PDF | (CS-2021:09:65405:3:0:NEW 23 Jan 2022) 
123 that allows evaluating websites that require authentication. We, therefore, propose ten

124

125

126

127

128

129

130

131

132

133

134

135

136

137

138

139

140

141

142

143

144

145

146

147

148

149

150

151

152

153

154

155

156

157

158

159

160

161

162

recommendations to improve the accessibility of the websites listed in the discussion section. Research (Abascal et al., 2019) related to Web accessibility evaluation argues that manual verification of compliance with accessibility guidelines is often complicated and unmanageable, so the authors suggest applying software tools that perform automatic accessibility evaluations. It presents a review of the main features of tools used for Web accessibility evaluation and presents an introspection of the future of accessibility tools.

The authors (Patricia Acosta-Vargas et al., 2019) suggest that verifying the accessibility of a Web site is a considerable challenge for accessibility specialists. Today, there are quantitative and qualitative methods for verifying whether a website is accessible. In general, the methods use automatic tools because they are low-cost, but they do not represent a perfect solution. The authors propose a heuristic method with a manual review supported by the Web Content Accessibility Guidelines 2.1. The evaluators concluded that the research could serve as a preliminary argument for upcoming analyses concerned with web accessibility heuristics.

Our investigation proposes an automatic review method using the WAVE Web Accessibility Evaluation Tool (WebAIM, 2021). Earlier studies by the authors (Patricia Acosta-Vargas et al., 2018) indicated that one of the best tools for automated review is WAVE, which allows you to identify any accessibility barriers, centered on the Web Content Accessibility Guidelines (WCAG) 2.1 (World Wide Web Consortium, 2018) that help in automatic review and evaluation by web content experts.

This preliminary study was applied to the 50 best-ranked e-commerce stores according to the ranking proposed by the ecommerceDB site (EcommerceDB, 2020), which contains detailed information on more than 20,000 stores from 50 countries and 13 categories.

\section{Web accessibility principles}

Previous studies indicate the increase of e-commerce in COVID-19 time; this accelerated growth has generated millions of e-commerce websites, but many sites are not accessible; therefore, it is essential to bear in mind the Web Content Accessibility Guidelines 2.1 (WCAG 2.1) proposed by the World Wide Web Consortium.

Web accessibility implies that people with incapacities can use the web. This process implies that they can recognize, identify, navigate, and relate to the website. WCAG 2.1 (World Wide Web Consortium, 2018) consists of 4 principles, 13 guidelines and 78 conformance such as compliance or success criteria, plus some techniques.

Principle 1- Perceptible refers to the website's contents and the interface design for all users. It includes the audiovisual contents, the interface, images, buttons, video players and other components that must be accessible, recognizable, and feasible by any individual in any condition, tool, and operating system.

Principle 2 - Operable, this means that a website should be as intuitive as possible, with options to perform an action or search for content. The more alternatives included in the site's navigation, the better its accessibility. In other words, the website must ensure all keyboard-based functionality and avoid designs that may cause epileptic seizures.

Peer] Comput. Sci. reviewing PDF | (CS-2021:09:65405:3:0:NEW 23 Jan 2022) 
163 Principle 3 - Understandable implies that the site includes legible and understandable elements,

164

165

166

167

168

169

170

171

172

173

174

175

176

177

178

179

180

181

182

183

184

185

186

187

188

189

190

191

192

193

194

195

196

197

198

199

200

201

202

203

both in the form and substance of the texts. It must contain fonts that all users can read in its form.

In addition, it should be predictable as to how the site works so that potential users do not waste time trying to guess how a tool works for better navigation.

Principle 4 - Robust Robustness refers to websites or applications that must be compatible with all browsers, operating systems, and devices, as well as assistive technology applications or digital ramps.

The four principles of accessibility contain 13 guidelines that support the goals of website designs to make content more accessible to users with disabilities. Each guideline includes success criteria that can be applied in situations for compliance testing in a contractual agreement. To meet accessibility requirements, three conformance levels are defined, with A being the lowest, AA being a medium level and acceptable by WCAG, and AAA being the highest (World Wide Web Consortium, 2018).

The documentation includes several techniques; the techniques are grouped into two classes 1) those that are sufficient to achieve the success criteria and 2) advisable techniques that allow the authors to better comply with the guidelines. In addition, some of the advisable techniques deal with accessibility barriers that the verifiable success criteria have not covered.

\section{Materials \& Methods}

In this research to evaluate the accessibility of e-commerce websites, we applied an automatic review method (World Wide Web Consortium (W3C), 2014) centered on a modification of the Website Accessibility Conformance Evaluation Methodology (WCAG-EM) 1.0.

We used Web Accessibility Evaluation Tool (WAVE) (WebAIM, 2021) with the extension for Google Chrome, which helps verify password-protected and highly dynamic pages. Utah State University developed the WAVE automatic evaluation tool to help find potential accessibility issues according to WCAG 2.1, facilitating manual evaluation. It should be noted that manual testing cannot be replaced, especially when it comes to accessibility, as it may be essential to test with end-users with disabilities. Accessibility validation was performed using guidelines based on Section 508 and WCAG 2.1; some phases of this methodology (Salvador-Ullauri et al., 2020) were tested in previous works of the authors related to serious games; the methodology for evaluating e-commerce websites is summarized in eight phases, as shown in Figure 2.

Figure 2 Methodology for evaluating e-commerce websites. Diagram for assessing accessibility in e-commerce websites.

Phase 1 Select e-commerce Websites. In this phase, we selected the 50 e-commerce websites that are in the top rankings according to the classification proposed by ecommerceDB (EcommerceDB, 2020). In this preliminary phase, we define the level of compliance with WCAG 2.1 (World Wide Web Consortium, 2018). In this case, we evaluated the AA level within the level accepted and recommended by WCAG 2.1. This knowledge can be improved to propose future work; we also determined the lowest configuration of web browser patterns, operating systems and assistive technologies with which the website should work during the testing phase. This case study used

Peer] Comput. Sci. reviewing PDF | (CS-2021:09:65405:3:0:NEW 23 Jan 2022) 
204 the Windows 10 operating system with Google Chrome browser version 95.0.4638.54 and screen 205 reader support.

206 Phase 2 Categorize the type of users. According to (Salvador-Ullauri et al., 2020), in this phase, 207 we involved three web accessibility experts with experience in the area since 2015, who have more 208 than ten scientific publications in web accessibility evaluations, serious games, and accessible 209 mobile applications. Discrepancies found in the automatic review of e-commerce sites were 210 resolved in consensus. Experts performed the automatic review with WAVE; as evaluated by 211 experts, WAVE is one of the best performing tools according to previous studies (Patricia Acosta212 Vargas et al., 2018). This phase identified the flow of events users interact with when browsing e213 commerce sites.

214 Phase 3 Define the test scenario. According to (Salvador-Ullauri et al., 2020), this phase 215 identifies the essential functionalities of the e-commerce website to help select the most 216 representative instances. The definition of the test scenario serves as the basis for the subsequent 217 selection of the e-commerce sites. In this case, we apply the following scenario: 1) We enter the 218 first page of the website. 2) We interact by selecting and purchasing products on the e-commerce 219 website. 3) We test how to fill out and submit the forms. 4) We check if account registration on 220 the e-commerce site is required.

221 Phase 4 Explore the e-commerce website. In this phase, the first page of each website was 222 explored. The evaluators explored the e-commerce website to understand its purpose, 223 functionality, and usage. Initial exploration of this phase was considered in Phase 1 by selecting a 224 representative sample, then refined in phase 5 by evaluating with WAVE. Involving accessibility 225 experts and website designers can help get the scans more efficiently. At first, cursory checks were 226 performed to help identify relevant web pages; later, a more detailed evaluation of each website 227 component was performed. Therefore, this phase is essential for evaluators to access all the 228 essential components and functionalities of the website.

229 Phase 5 Evaluate with WAVE. In this phase, the experts used WAVE to evaluate the home page 230 of each e-commerce website. The assessment was conducted in March 2021; during this phase, 231 the evaluators audited the sample e-commerce websites and the states of the websites selected in 232 phases 1 and 4.

233 The evaluation was conducted following the WCAG 2.1 conformance requirements at the AA 234 level previously defined in phase 1. The conformance level, web pages, processes and 235 technologies, and compatibility with accessibility and non-interference were considered. In this 236 phase, it was essential to know the WCAG 2.1 (World Wide Web Consortium, 2018) conformance 237 requirements and the experience of accessibility experts. In addition, the authors classified 238 accessibility barriers by matching the WCAG 2.1 principles, guidelines, and success criteria, 239 which were then validated with WAVE results.

240 Phase 6 Record evaluation data. In this phase, the assessment data was documented in a 241 spreadsheet to organize a dataset available in Mendeley (P. Acosta-Vargas et al., 2021). The 242 dataset includes information with the names of the audited websites, the URLs of the e-commerce 243 sites, and the evaluation data used to replicate this study as part of good practices that help 
244 researchers. The set organizes the information into spreadsheets, containing 1) The e-commerce 245 websites evaluated. 2) The results of the e-commerce websites evaluated with WAVE. 3) The map 246 of the number of e-commerce websites per country. 4) The diagram of the accessibility evaluation 247 process with WAVE. 5) A summary of the evaluation of e-commerce websites. 6) The accessibility 248 principles of WCAG 2.1. 7) Accessibility barriers identified when evaluating with WAVE. 8) E249 commerce websites versus compliance. 9) E-commerce websites with errors and contrast errors. 250 10) The number of alerts, features, structural elements and ARIA. 11) E-commerce websites and 251 the relation to accessibility levels.

252 Phase 7 Classify and analyze data. Following previous work by the authors (Salvador-Ullauri et 253 al., 2020), data related to accessibility principles, success criteria, and accessibility levels are 254 organized in this phase. This information is detailed in the results section and discussed in the 255 256

257

258

259 discussion section. Also, the e-commerce websites were classified by 1) The countries to which each domain corresponds according to the registered URL. 2) The severe errors in need of correction to remove accessibility barriers. 3) Contrast errors that make access difficult for visually impaired users. 4) The ranking in which they are placed and the level of accessibility. The data analysis was performed with Microsoft Excel version 365 MSO 16.0.14326.20504, with macros, advanced functions, tables, and dynamic graphs.

261 Phase 8 Suggest accessibility improvements. In this phase, proposals for improvements to the e262 commerce websites were presented. The improvements are detailed in the discussion section.

\section{Results}

264

265

266

267

268

269

270

271

272

273

274

275

276

277

278

279

280

281

282

283

This research was applied to a sample of the top 50 e-commerce websites taken from ecommerceDB; which contains information on more than 20,000 e-shops from around 50 countries. It is divided into several categories such as revenue and competitor analysis, market development, performance and traffic indicators, vendor submission, payment options, social media activity and SEO information. The ecommerceDB.com database also covers e-commerce market analysis, customer behaviors and buying patterns, market trends and company histories. Table 1 contains the sites that were evaluated with WAVE.

Table 1 E-commerce websites. Presents a sample of 50 e-commerce stores according to the ranking of the classification proposed by ecommerceDB, followed by the name of the electronic store, the URL, and the acronym.

The evaluation of the accessibility of e-commerce stores was carried out with the WAVE automatic review tool. Rich Internet applications tend to dynamically update the Document Object Model (DOM) structure, which is why the method used by WAVE to analyze the rendered DOM of pages uses heuristics and logic to detect end-user accessibility barriers considering WCAG 2.1 (World Wide Web Consortium, 2018). All automatic review tools, including WAVE, have limitations; they can detect barriers in 35\% of possible compliance failures (WebAIM, 2021). The method applied in evaluating the accessibility of e-commerce stores was based on a modification of the (World Wide Web Consortium (W3C), 2014) WCAG-EM 1.0; our method consists of an eightphase process detailed in Figure 2. 
284 Table 2 presents the data obtained from the accessibility evaluation of e-commerce websites with 285 WAVE. It contains the number of WCAG 2.1 compliance failures that may affect specific users. 286 Web developers should correct the barriers identified in the evaluation to make the e-commerce 287 site accessible and inclusive. The contrast errors found in this study are related to the text that 288 violates WCAG 2.1 contrast requirements. The term alerts are related to elements that may cause 289 accessibility problems; in this case, the evaluator is the one who decides the impact of the 290 accessibility of the website. Features imply that elements can improve accessibility when 291 implemented correctly. Structural elements are related to some title of a web page, indicating that 292 it has been marked as a top-level title or related to several milestones. Finally, the ARIA element 293 presents information about accessibility for people with disabilities; in such a way, it influences 294 accessibility when misused.

295

296

297

298

299

300

301

302

303

304

305

Table 2 E-commerce websites evaluated. It presents a sample of 50 e-commerce stores according to the ranking of the classification proposed by ecommerceDB, followed by the acronym, errors, contrast errors, alerts, features, structural elements, ARIA, and the country to which each e-commerce corresponds.

Figure 3 shows the number of e-commerce sites by country, taken as a sample for the accessibility evaluation. The most significant number of e-commerce sites evaluated corresponds to the United States, with 24 sites representing $48 \%$ of the total, followed by the United Kingdom, with eight sites representing 16\%. With six e-commerce sites, Greater China accounts for $12 \%$ in third place. Next, Germany, with three sites, accounts for $6 \%$, followed by France and Russia, with two sites each, representing $8 \%$ of the total. Lastly, Brazil, Canada, Italy, Japan and Spain, with one ecommerce site, account for $10 \%$.

314

315

316

317

318

319

320

321

322

323

324

325

326
Figure 3 Map of the number of e-commerce sites taken by the country. The map presents the countries taken as part of the sample to evaluate accessibility according to the classification proposed by ecommerceDB. The sky blue color indicates the country with the highest number of e-commerce sites, the yellow color the midpoint and the pink color the lowest number of e-commerce sites.

Figure 4 shows two categories of barriers, warning and serious barriers; the most significant warning barriers are ARIA, Structural Elements, Features and Alerts. These barriers do not affect accessibility to a high degree, and correcting them is unnecessary. The serious barriers with a high number are Contrast Errors with 1721 barriers, representing 7.4\% (pink bars) and Errors with 1229, corresponding to $5.3 \%$ (sky blue bars), which must be corrected urgently for e-commerce sites to reach an acceptable level of accessibility. ARIA attributes (World Wide Web Consortium, 2018) add semantic information to the elements of a website, specifically for properties that help to inform: 1) The state of an element of the graphical interface. 2) The content of a section that may change when there is user interaction. 3) The elements that are part of a drag-and-drop interface. 4) The relationships between document elements.

Figure 4 Evaluation of accessibility with WAVE. It shows the barriers related to Errors (sky blue bars) and Contrast Errors (pink) that should be corrected urgently to improve accessibility. Alerts (yellow), Features (gray), Structural Elements (orange) and ARIA (blue) that can be corrected depending on the evaluator's criteria. 
327

328

329

330

331

332

333

334

335

336

337

338

339

340

341

342

343

344

345

346

347

348

349

350

351

352

353

354

355

356

357

358

359

360

361

362

363

364

365

366

367

368

369

370

Table 3 summarizes the barriers identified during the evaluation of the e-commerce sites with WAVE. Table 3 includes the barriers, success criteria, level, principle, and total barriers of the 50 e-commerce websites assessed. Table 3 comprises the success criteria composed of three numbers; the first is associated with the accessibility principle, the second to the guideline, and the third to the success criteria related to the accessibility barrier.

Table 3 Summary of the evaluation of e-commerce websites. Shows the summary of accessibility barriers identified by applying the WAVE automatic review tool.

Figure 5 shows a synopsis of the accessibility principles recognized in the assessment of ecommerce websites. The most neglected accessibility principle is perceivable, representing $83.1 \%$ of the total, followed by operable with $13.7 \%$, in third place is robust with $1.7 \%$, and finally, understandable with $1.5 \%$.

Figure 5 Accessibility evaluation using WAVE. It presents detailed evaluation results with accessibility principles according to WCAG 2.1 .

Figure 6 summarizes the barriers identified in the accessibility evaluation. The most affected accessibility barrier corresponds to Contrast with $54.4 \%$, followed by Non-text Content, representing $25.6 \%$, in third place is Link purpose, representing $11.6 \%$ of the total. The rest of the barriers, such as info and relationships, name, role, value, headings and labels, labels or instructions, bypass blocks, keyboard, the language of page and error identification, correspond to values lower than $3.1 \%$.

Figure 6 Accessibility barriers identified when evaluating with WAVE. It presents the results related to the success criteria according to WCAG 2.1.

Figure 7 presents the e-commerce sites and the level of web accessibility; among the top ten most accessible websites according to this analysis with WAVE, we have Sainsbury's Supermarkets, Walmart, Target Corporation, Macy's, IKEA, H \& M Hennes, Chewy, The Kroger, QVC, and Nike.

Figure 7 E-commerce websites evaluated. It presents the level of web accessibility of the ten most accessible websites evaluated with the WAVE automatic review tool.

In addition, the correlation between the ranking of e-commerce sites and accessibility barriers was analyzed. In Table 4, the test statistic p $>0.05$ for Errors, Contrast Errors and Ranking have a normal distribution despite their variability. While applying Lilliefors significance correction, the variables Errors and Contrast Errors $\mathrm{p}<0.05$ confirm that they do not have a normal distribution. However, the variable Ranking with Lilliefors significance correction has a $\mathrm{p}>0.05$, confirming a normal distribution.

Table 4 Normality tests. Show normality tests for Lilliefors significance correction. We applied for errors, contrast errors, and ranking.

Peer] Comput. Sci. reviewing PDF | (CS-2021:09:65405:3:0:NEW 23 Jan 2022) 
371

372

373

374

375

376

377

378

379

380

381

382

383

384

385

386

387

388

389

390

391

392

393

394

395

396

397

398

399

400

401

402

403

404

405

406

407

408

409

410

411

Table 5 presents Spearman's non-parametric correlation between e-commerce website ranking and accessibility barriers. In this case, the correlation is significant for accessibility barriers at the 0.05 level (bilateral).

Table 5 Spearman correlation. It shows Spearman's non-parametric correlation between the ranking of e-commerce websites and accessibility barriers. Spearman's Rho correlation is 0.329 , indicating that the correlation is low positive.

In analyzing the accessibility of e-commerce websites, we applied multivariate descriptive statistics and pivot tables with the Excel tool. In addition, to analyze the correlation between the ranking of e-commerce websites and accessibility barriers, we applied the IBM SPSS Statistics version 25 statistical software with which we applied the Kolmogorov-Smirnov and Lilliefors significance correction. We found a non-parametric correlation, so we applied Spearman's Rho between the ranking of e-commerce websites and the accessibility barriers of e-commerce websites. The correlation is 0.329 , which indicates that the correlation is low positive.

\section{Discussion}

Concerning the modification made in WCAG-EM 1.0, three additional phases were included. By applying WAVE in phase 5, it is possible to perform automatic checks, which considerably reduces review time and detects numerous problems that would take more time and would be difficult to identify manually. Our methodology allows linking WCAG 2.1 criteria to accessibility barriers; this method can be applied throughout the website development cycle.

Currently, e-commerce sites have become essential tools to perform commercial transactions due to the COVID-19; with the findings obtained, it is evident that web designers and developers need to utilize the WCAG 2.1 (World Wide Web Consortium, 2018) to have more accessible and inclusive e-commerce sites. We identified that there is a significant number of e-commerce sites that occupy the top positions in the most developed countries such as the United States, United Kingdom, Greater China, Germany, Russia, and France; however, occupying the top positions do not guarantee that they comply with the WCAG 2.1 accessibility standards.

The most accessible store is Sainsbury's Supermarkets, located in the United Kingdom with zero "Errors", followed by Walmart, Target, Chewy, IKEA, and Macy's, from the United States and H \& M from Germany with one "Errors", the rest of the e-commerce websites have more than one "Errors" and more than six "Contrast Errors".

In the evaluation of e-commerce websites, it was found that the most common errors are related to "Contrast errors", representing 54.4\% of the total, in second place "Non-text Content", corresponding to $25.6 \%$, "Link Purpose" corresponds to $11.6 \%$ and "Info and Relationships" with $3.1 \%$ of the total.

Of the 50 e-commerce websites evaluated, $44.2 \%$ of the total comply with level "A" for accessibility and 55.8\% with level "AA"; none of the sites evaluated reach level "AAA".

The highest number of accessibility barriers are condensed in the "perceivable" principle, representing $83.1 \%$ of the total, while $16.9 \%$ are distributed among the "operable," "robust," and "understandable" principles. This finding implies that more barriers are related to problems for

Peer] Comput. Sci. reviewing PDF | (CS-2021:09:65405:3:0:NEW 23 Jan 2022) 
412 users with low vision, including older adults (Padmanaban et al., 2019); vision deteriorates with 413 age due to the eye's normal aging process. The existence of ocular degenerative diseases such as 414 glaucoma, age-related macular degeneration, diabetic retinopathy, age-related cataracts, and 415 cardiovascular accidents can mainly trigger a decrease in visual acuity and the visual field.

416 One of the most frequently repeated barriers on e-commerce sites is contrast and color usage, vital 417 parameters for web accessibility. In contrast, most of the world's users are visually impaired. 418 According to World Health Organization (World Health Organization (WHO), 2021), worldwide, 419 at least 2.2 billion people have near or distance vision problems.

420 Achieving accessibility on e-commerce websites is an excellent challenge, so it is essential to apply 421 the contrast ratio, which measures the difference in "luminance" or perceived brightness between 422 two colors. The difference in brightness is expressed as a ratio varying from 1:1. WCAG 2.1 423 suggests addressing contrast with the three success criteria, 1.4.3 Contrast (minimum), 1.4.6 424 Contrast (enhanced) and 1.4.11 Contrast without text. In WCAG 2.1, it is suggested that 4.5:1 is 425 the minimum required. Possibly some of these combinations are not very readable for all users.

426 For an e-commerce website to be accessible (World Wide Web Consortium, 2018), it must meet 427 level AA for accessibility; the evaluated e-commerce websites do not present any accessibility 428 statement or specify whether they officially comply. Since the home page of these e-commerce 429 sites is the user's entry point, it should be a primary objective for enhancements in terms of 430 accessibility. Improving e-commerce websites should be a responsibility that companies take on, 431 as it enhances the user experience and reduces the technology gap that people with disabilities may 432 experience.

433 Accessibility issues can be reduced with the following recommendations 1) Improve contrast by 434 considering the colors and contrasts of the screen, checking that they are displayed correctly on all 435 devices. 2) Eliminate time limits, or at least lengthen them. It is essential to consider that users 436 with disabilities need more time to browse online. 3) Always adding the option to "skip content" 437 is very useful for users who access the Internet with screen readers and avoid content that does not 438 interest them. 4) Provide transcripts of texts: in addition to subtitling videos, it is advisable to 439 include transcripts so that the hearing impaired can read the video content at their own pace. 5) 440 Add captions to graphics: especially those whose description does not conform to the "alt" 441 attribute. The use of the "Alt" attribute, called "alternative text," is essential for blind users who 442 use screen readers. 6) Avoid using red to highlight important things; it would be fine if no people 443 had color blindness problems. A good accessibility option is to use more giant letters or 444 representative icons. 7) Write contents oriented to any reader, with and without disabilities. 8) Use 445 legible fonts larger than 15px. 9) Avoid using paragraphs longer than four lines. 10) Use images 446 and diagrams that help the reader understand the content better.

447 This study brings originality since the 50 top-ranked e-commerce sites were evaluated. Nowadays, 448 e-commerce websites must have accessibility policies and standards; several transactions are made 449 electronically due to the pandemic.

450 This research can guide developers and designers of e-commerce websites to spread the use of 451 WCAG 2.1, which is intended to cover a more extensive set of recommendations to make the web 
452 more accessible. WCAG 2.1 can be considered as a superset containing WCAG 2.0. Therefore, as

453 WCAG 2.1 extends WCAG 2.0, there are no incompatible requirements between one version.

454 Limitations

455 This research has a fundamental limitation; it was evaluated using the WAVE automated review 456 tool. Despite being a powerful tool that helps organizations improve the accessibility of websites 457 for people with disabilities, WAVE cannot tell whether web content is accessible; only a human 458 being can determine true accessibility. This evaluation did not include testing with users with 459 disabilities; three accessibility experts conducted accessibility testing. No additional hardware or 460 digital ramps were used in this study to achieve greater accessibility during the website evaluation 461 process.

\section{Conclusions}

463 We consider the research relevant, especially during the COVID-19 period, when e-commerce is

464

465

466

467

468

469

470

471

472

473

474

475

476

477

478

479

480

481

482

483

484

485

486

487

488

489

490

491 considered the leading solution in confining and indirectly improving the global economy. The procedure for evaluating e-commerce websites with the WAVE tool can be applied to any website to make it more than accessible. We recommend performing evaluations with heuristic methods based on WCAG 2.1 (World Wide Web Consortium, 2018) accessibility barriers and automated reviews with users with different disabilities. We found that $55.8 \%$ of the websites reach the "AA" level suggested by WCAG 2.1. We found a low positive correlation between the rating of ecommerce websites and accessibility barriers according to Spearman's Rho of 0.329 . The study revealed that $25.6 \%$ of e-commerce websites present images of the products they offer and that $54.4 \%$ of the sites present contrast problems related to the perception principle, which need to be solved urgently to make the sites more inclusive. Finally, we suggest that business people, governments, and academia work in multidisciplinary teams to generate laws and regulations related to web accessibility that would benefit all users, especially those with disabilities.

\section{Future Work}

It is recommended to 1) Perform tests with other automatic review tools and compare the results obtained for future research. 2) Conduct tests with users with different disabilities. 3) Build a software tool that includes artificial intelligence algorithms that help the software learn the heuristics that may cause accessibility barriers. 4) Include hardware limitations and interstitial advertising in the study.

\section{Acknowledgments}

This research was funded by Universidad de Las Américas-Ecuador as an internal research project INI.PAV.20.01.

\section{Competing Interests}

The authors declare there are no competing interests.

\section{Author Contributions}

Conceptualization: Patricia Acosta-Vargas, Luis Salvador-Ullauri. Methodology: Patricia Acosta-Vargas, Luis Salvador-Ullauri. Investigation: Patricia Acosta-Vargas, Luis SalvadorUllauri, Belén Salvador-Acosta, Janio Jadán-Guerrero. Visualization: Patricia Acosta-Vargas, Luis Salvador-Ullauri. Supervision: Patricia Acosta-Vargas. Writing —original draft: Patricia 
492

493

494

495

496

497

498

499

500

501

502

503

504

505

506

507

508

509

510

511

512

513

514

515

516

517

518

519

520

521

522

523

524

525

526

527

528

529

530

531

532

533

534

535

536

Acosta-Vargas, Luis Salvador-Ullauri, Belén Salvador-Acosta, Janio Jadán-Guerrero. Writingreview \& editing: Patricia Acosta-Vargas, Luis Salvador-Ullauri, Belén Salvador-Acosta, Janio Jadán-Guerrero.

\section{Ethics}

This research uses only publicly available information and no access to any other source besides the Mendeley repository dataset. This research constitutes a study of e-commerce websites (i) does not interact with any users; (ii) does not infer any new personal information; therefore, this study is exempt from an institutional review board. This research provides a data-driven audit to make better-informed decisions about accessibility on e-commerce websites, with the expected benefit of overcoming accessibility barriers faced by users of e-commerce websites in the future.

\section{Data Availability}

All data needed to evaluate the conclusions in the paper are present in the paper and the

Supplementary Materials.

\section{Supplementary Materials}

http://dx.doi.org/10.17632/s33r57h5zm.2

\section{References}

Abascal, J., Arrue, M., \& Valencia, X. (2019). Tools forWeb Accessibility Evaluation. In Web Accessibility (pp. 479-503). Springer London. https://doi.org/10.1007/978-1-4471-7440-0

Acosta-Vargas, P., Salvador-Acosta, B., Salvador-Ullauri, L., Gonzalez, M., \& Jadan-Guerrero, J. (2021). (Dataset) Web accessibility of the e-commerce website. Mendeley Data, V1. https://doi.org/10.17632/s33r57h5zm.2

Acosta-Vargas, Patricia, Acosta, T., \& Lujan-Mora, S. (2018). Challenges to assess accessibility in higher education websites: A comparative study of Latin america universities. IEEE Access, 6, 36500-36508. https://doi.org/10.1109/ACCESS.2018.2848978

Acosta-Vargas, Patricia, Antonio Salvador-Ullauri, L., \& Lujan-Mora, S. (2019). A Heuristic Method to Evaluate Web Accessibility for Users with Low Vision. IEEE Access, 7, 125634-125648. https://doi.org/10.1109/ACCESS.2019.2939068

Alshamari, M. (2016). Accessibility evaluation of Arabic e-commerce web sites using automated tools. Journal of Software Engineering and Applications, 9(9), 439-451. https://doi.org/10.4236/jsea.2016.99029

Andersen, K., Hoss, H., \& Bridge, C. (2020). Web Accessibility Guide. UNSW Sydney. https://doi.org/10.26288/5f9a27ac71839

EcommerceDB. (2020). Store Ranking \& Overview. https://ecommercedb.com/en/ranking/ww/all

Google. (2021). Google Trends. https://rends.google.com/trends/explore?date=today 5$\mathrm{y} \& \mathrm{q}=$ accessibility,e-commerce,WCAG

Munkova, D., Munk, M., Benko, L., \& Hajek, P. (2021). The role of automated evaluation techniques in online professional translator training. PeerJ Computer Science, 7, e706.

Oliveira, R. P., Afonso, A. P., \& Pinto, A. (2020). E-Commerce Website Accessibility Evaluation: Case Study in Portugal. Escola de Verão Em Transformação Digital, 1-14.

Padmanaban, N., Konrad, R., \& Wetzstein, G. (2019). Autofocals: Evaluating gaze-contingent eyeglasses for presbyopes. Science Advances, 5(6), eaav6187.

Padure, M., \& Pribeanu, C. (2020). Comparing six free accessibility evaluation tools. Informatica Economica, 24(1), 15-25. 
537

538

539

540

541

542

543

544

545

546

547

548

549

550

551

552

553

554

555

556

557

558

559

560

561

562

563

564

565

566

567

568

569

Paștiu, C., Oncioiu, I., Gârdan, D., Maican, S., Gârdan, I., \& Muntean, A. (2020). The Perspective of E-Business Sustainability and Website Accessibility of Online Stores. Sustainability, 12(22), 9780. https://doi.org/10.3390/su12229780

Paz, F., Paz, F. A., Moquillaza, A., Collantes, L., Arenas, J. J., \& Villanueva, D. (2021). Comparison of Accessibility Tools for the Evaluation of E-Commerce Websites. International Conference on Intelligent Human Systems Integration, 876-881.

Pollák, F., Konečný, M., \& Ščeulovs, D. (2021). Innovations in the Management of ECommerce: Analysis of Customer Interactions during the COVID-19 Pandemic. Sustainability, 13(14), 7986. https://doi.org/10.3390/su13147986

Salvador-Ullauri, L., Acosta-Vargas, P., Gonzalez, M., \& Luján-Mora, S. (2020). Combined method for evaluating accessibility in serious games. Applied Sciences (Switzerland), 10(18). https://doi.org/10.3390/APP10186324

Statista. (2020). Coronavirus impact on retail e-commerce website traffic worldwide as of June 2020, by average monthly visits. https://www.statista.com/statistics/1112595/covid-19impact-retail-e-commerce-site-traffic-global/

Statista. (2021). Global retail e-commerce sales 2014-2024. https://www.statista.com/statistics/379046/worldwide-retail-e-commerce-sales/

Villa, R., \& Monzón, A. (2021). Mobility Restrictions and E-Commerce: Holistic Balance in Madrid Centre during COVID-19 Lockdown. Economies, 9(57). https://doi.org/10.3390/economies9020057

WebAIM. (2021). WAVE Web Accessibility Evaluation Tool. https://wave.webaim.org/

World Health Organization (WHO). (2017). 10 facts on disability. World Health Organization. https://www.who.int/features/factfiles/disability/en/

World Health Organization (WHO). (2021). Blindness and vision impairment. https://www.who.int/news-room/fact-sheets/detail/blindness-and-visual-impairment

World Wide Web Consortium. (2018). Web Content Accessibility Guidelines (WCAG) 2.1. https://www.w3.org/TR/WCAG21/

World Wide Web Consortium (W3C). (2014). Website Accessibility Conformance Evaluation Methodology (WCAG-EM) 1.0. https://www.w3.org/TR/WCAG-EM/

Xu, J. (2020). Comparing Web Accessibility between Major Retailers and Novelties for ECommerce. Digitala Vetenskapliga Arkivet. https://www.divaportal.org/smash/get/diva2:1436863/FULLTEXT01.pdf 
Figure 1

Figure 1 The trend in Google Trends for terms related to accessibility, e-commerce, and WCAG.

Diagram of the trend of the terms in the last five years worldwide.

\begin{tabular}{l|l|l|l|}
$\begin{array}{l}\text { accessibility } \\
\text { Search term }\end{array} \quad \vdots$ & $\begin{array}{l}\text { e-commerce } \\
\text { Search term }\end{array}$ & $\vdots$ & $\begin{array}{l}\text { WCAG } \\
\text { Search term }\end{array}$
\end{tabular}

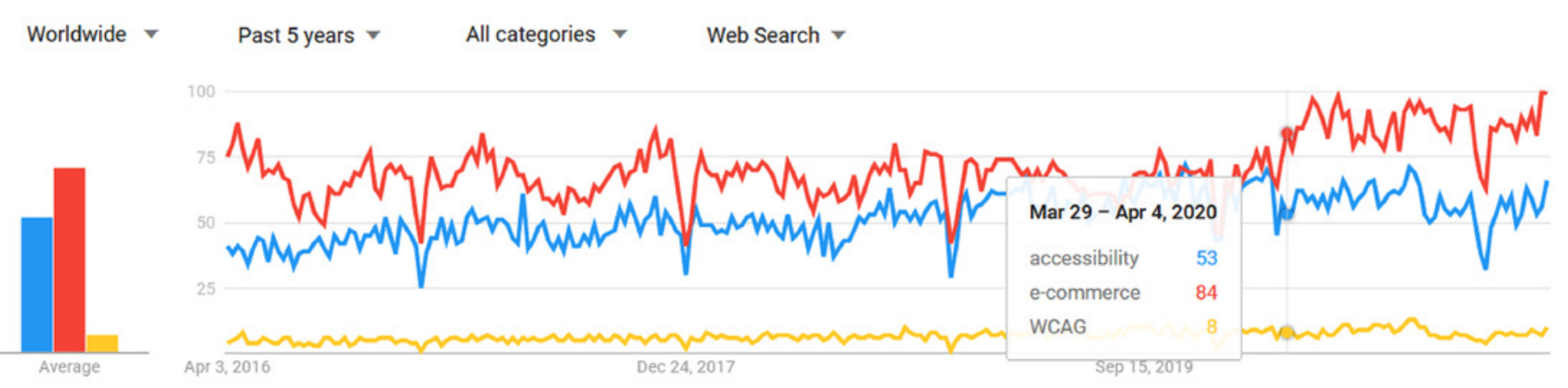




\section{Figure 2}

Figure 2 Methodology for evaluating e-commerce websites.

Diagram for assessing accessibility in e-commerce websites. 
Phase 1

\section{Select e-commerce} Websites

Phase 2

Categorize the type of

\section{users}

Phase 3

Define the test scenario

Phase 4 Explore the e-commerce Website

Phase $5 \quad$ Evaluate with WAVE

Phase 6 Record evaluation data

Phase 7 Classify and analyze data

Phase 8

Suggest accessibility improvements 


\section{Figure 3}

Figure 3 Map of the number of e-commerce sites taken by the country.

The map presents the countries taken as part of the sample to evaluate accessibility according to the classification proposed by ecommerceDB. The sky blue color indicates the country with the highest number of e-commerce sites, the yellow color the midpoint and the pink color the lowest number of e-commerce sites.

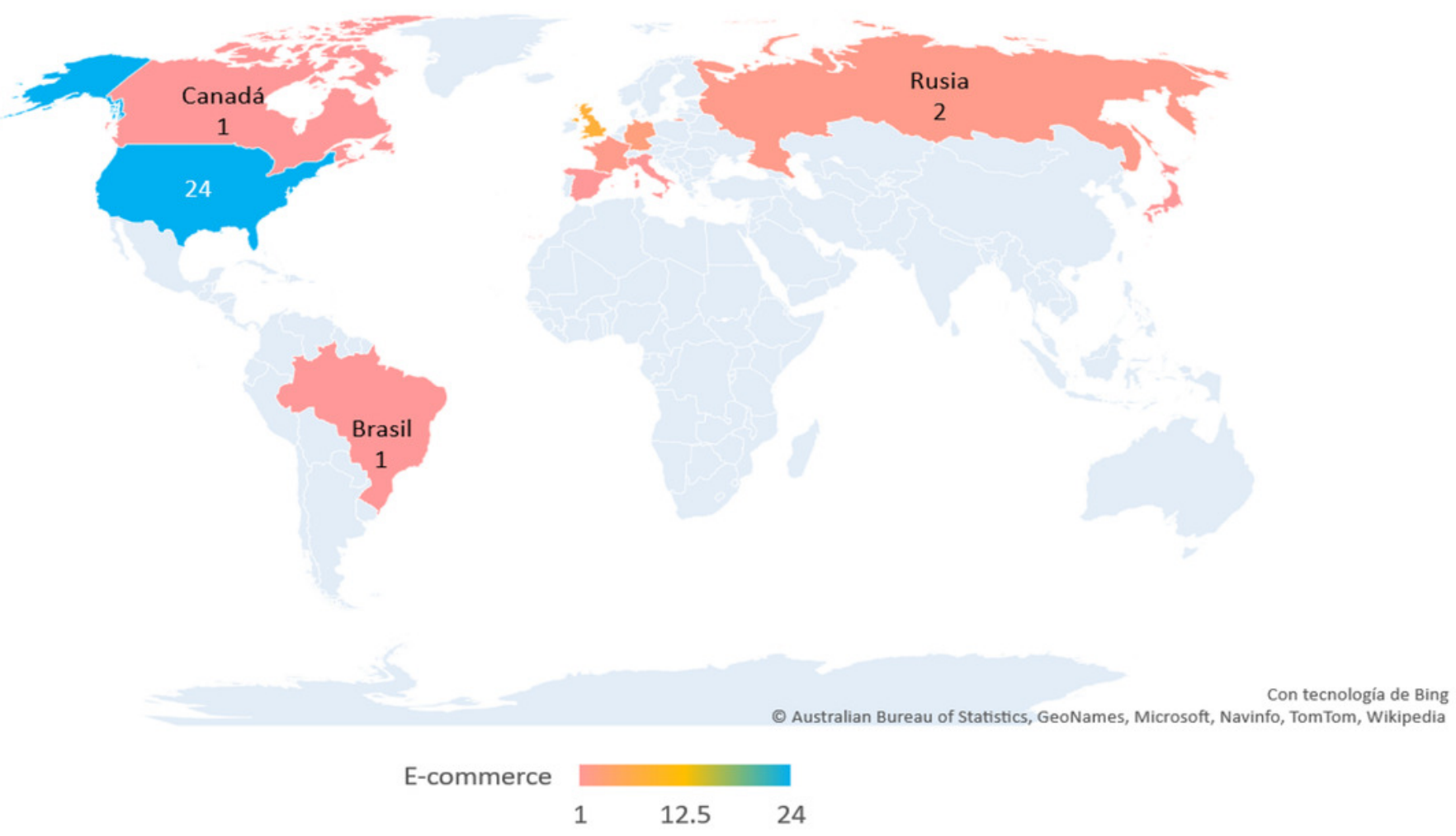




\section{Figure 4}

Figure 4 Evaluation of accessibility with WAVE.

It shows the barriers related to Errors (sky blue bars) and Contrast Errors (pink) that should be corrected urgently to improve accessibility. Alerts (yellow), Features (gray), Structural Elements (orange) and ARIA (blue) that can be corrected depending on the evaluator's criteria.

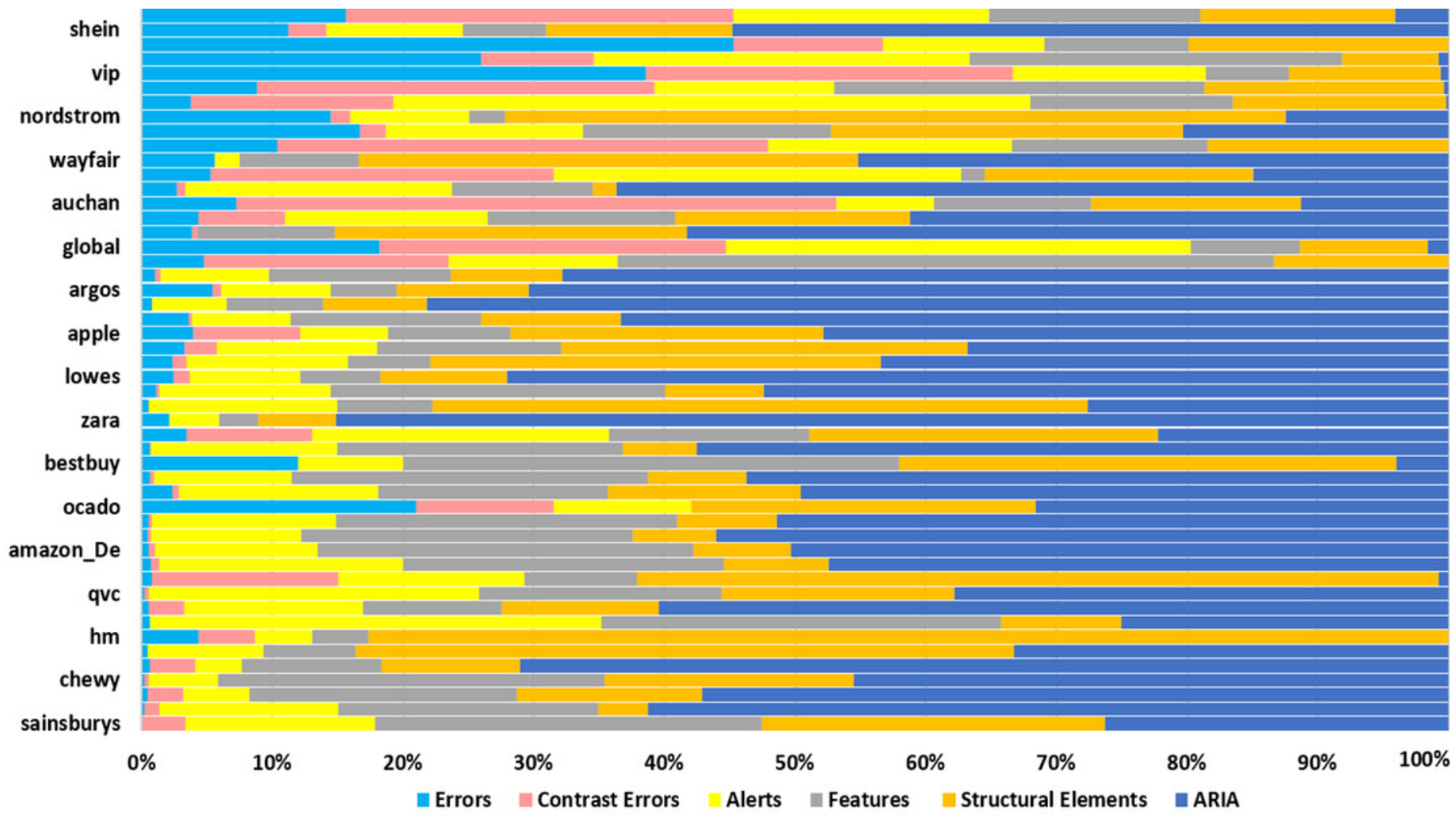


Figure 5

Figure 5 Accessibility evaluation using WAVE.

It presents detailed evaluation results with accessibility principles according to WCAG 2.1.

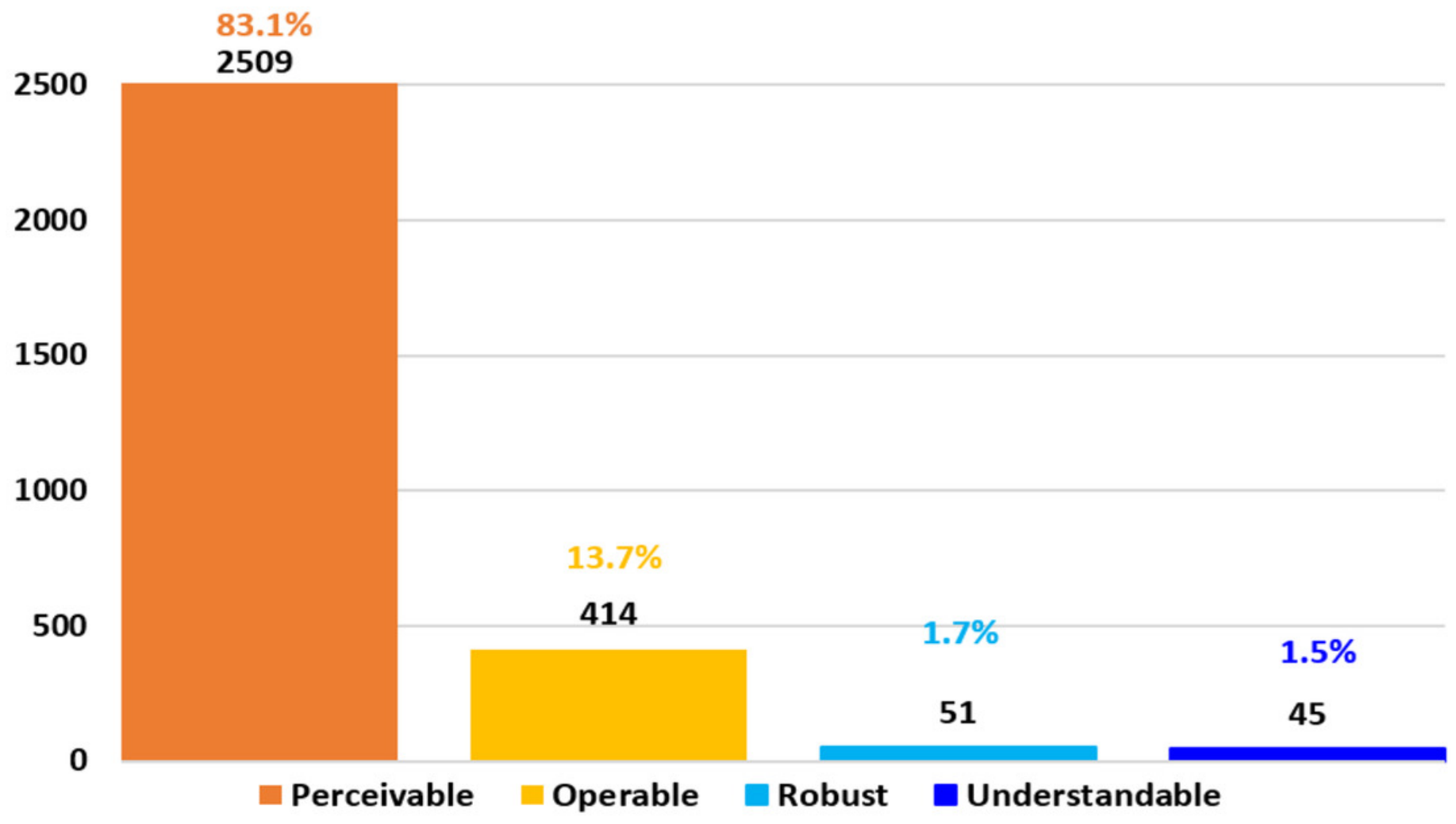


Figure 6

Figure 6 Accessibility barriers identified when evaluating with WAVE.

It presents the results related to the success criteria according to WCAG 2.1.

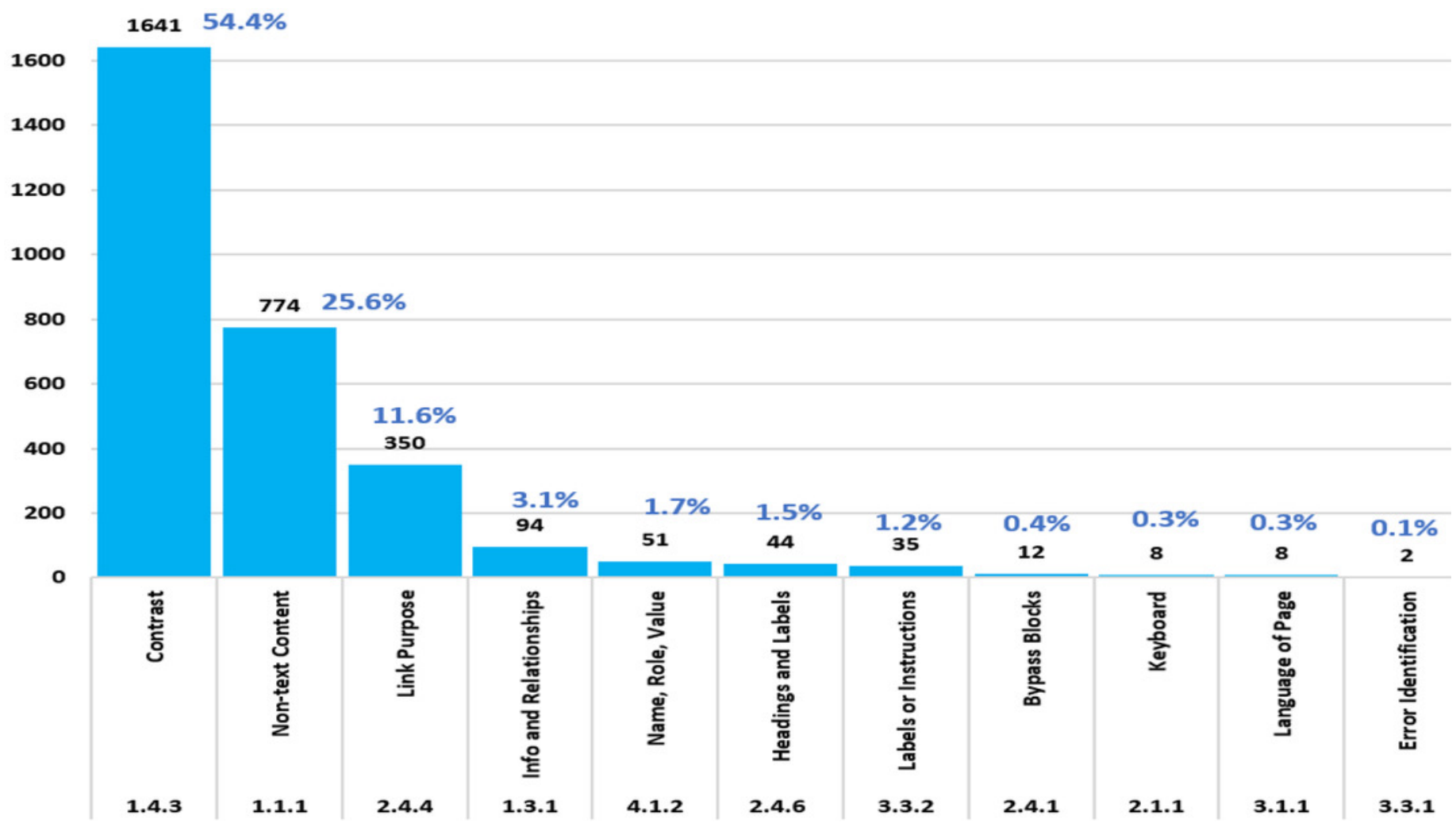




\section{Figure 7}

Figure 7 E-commerce websites evaluated.

It presents the level of web accessibility of the ten most accessible websites evaluated with the WAVE automatic review tool.

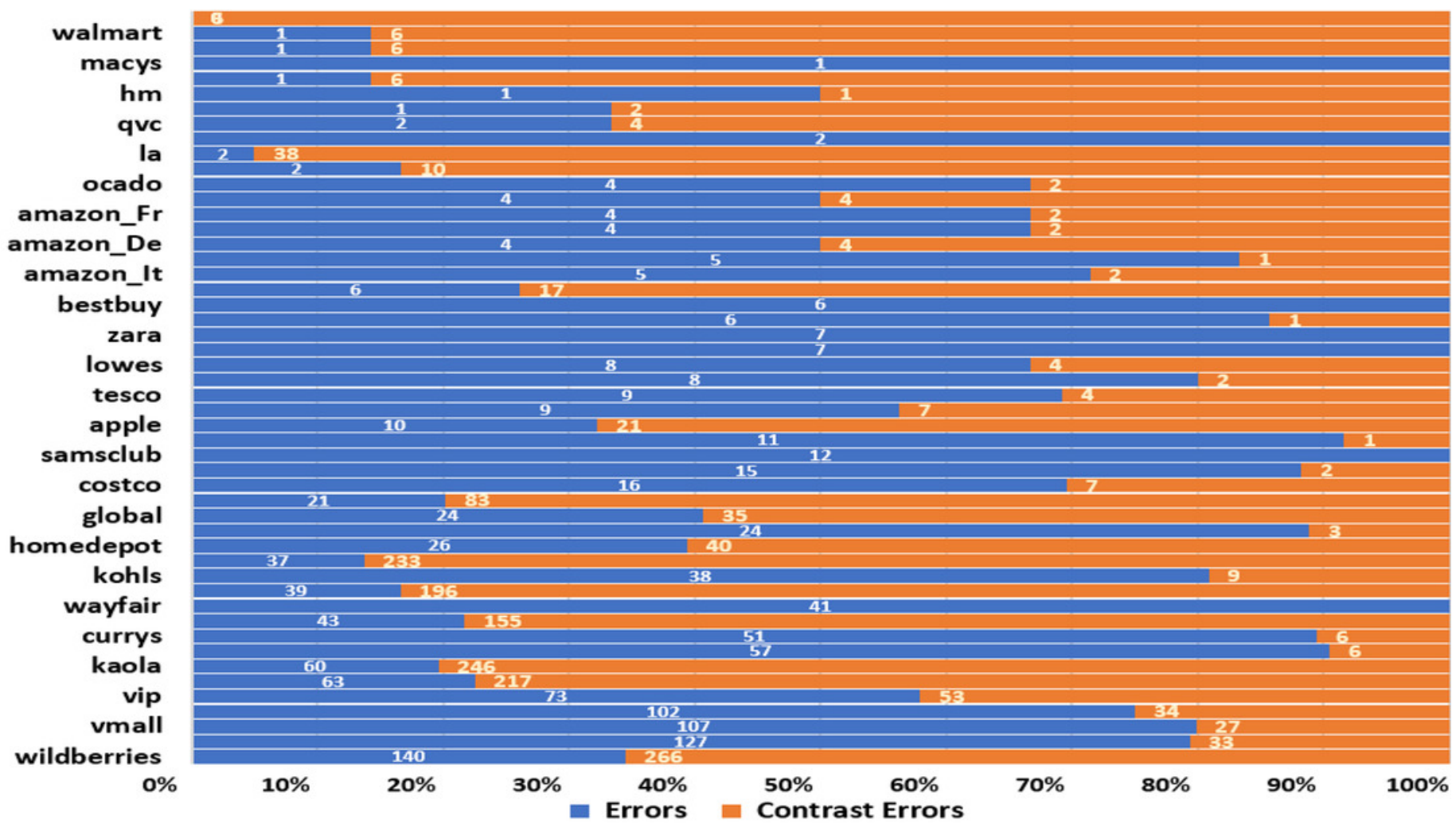




\section{Table $\mathbf{1}$ (on next page)}

Table 1 E-commerce websites.

Presents a sample of 50 e-commerce stores according to the ranking of the classification proposed by ecommerceDB, followed by the name of the electronic store, the URL, and the acronym. 
1 Table 1 E-commerce websites. Presents a sample of 50 e-commerce stores according to the ranking of the 2 classification proposed by ecommerceDB, followed by the name of the electronic store, the URL, and the acronym.

\begin{tabular}{|c|c|c|c|}
\hline \# & Online-Store & URL & Acronym \\
\hline 1 & Amazon.com, Inc. & https://www.amazon.com/ & amazon_Us \\
\hline 2 & $\begin{array}{l}\text { Beijing Jingdong } 360 \text { Degree E-Commerce Co., } \\
\text { Ltd. }\end{array}$ & https://global.jd.com/ & global \\
\hline 3 & Apple, Inc. & https://www.apple.com/ & apple \\
\hline 4 & Walmart, Inc. & https://www.walmart.com/ & walmart \\
\hline 5 & Suning Tesco Group Co., Ltd. & https://www.suning.com/ & suning \\
\hline 6 & Amazon EU S.à r.l. & https://www.amazon.de/ & amazon De \\
\hline 7 & Amazon EU S.à r.l. & https://www.amazon.co.uk/ & amazon_Uk \\
\hline 8 & $\begin{array}{l}\text { Guangzhou Vipshop Electronic Commerce Co., } \\
\text { Ltd. }\end{array}$ & https://www.vip.com/ & vip \\
\hline 9 & Target Corporation & https://www.target.com/ & target \\
\hline 10 & Amazon.com Services, LLC & https://www.amazon.co.jp/ & amazon_Jp \\
\hline 11 & $\begin{array}{l}\text { Guangdong Midea Network } \\
\text { Technology Co., Ltd. }\end{array}$ & https://www.midea.cn/ & midea \\
\hline 12 & The Home Depot, Inc. & https://www.homedepot.com/ & homedepot \\
\hline 13 & Best Buy Co., Inc. & https://www.bestbuy.com/ & bestbuy \\
\hline 14 & Amazon.com.ca, Inc. & https://www.amazon.ca/ & amazon $\mathrm{Ca}$ \\
\hline 15 & Wayfair, LLC & https://www.wayfair.com/ & wayfair \\
\hline 16 & Amazon EU S.à r.l. & https://www.amazon.fr/ & amazon_Fr \\
\hline 17 & Costco Wholesale Corporation & https://www.costco.com/ & costco \\
\hline 18 & Chewy, Inc. & https://www.chewy.com/ & chewy \\
\hline 19 & Nike, Inc. & https://www.nike.com/xl/ & nike \\
\hline 20 & Inter IKEA Systems B.V. & https://www.ikea.com/ & ikea \\
\hline 21 & Tesco Stores, Ltd. & https://www.tesco.com/ & tesco \\
\hline 22 & Macy's, Inc. & https://www.macys.com/ & macys \\
\hline 23 & Argos, Ltd. & https://www.argos.co.uk/ & argos \\
\hline 24 & Wildberries, OOO & https://www.wildberries.ru/ & wildberries \\
\hline 25 & Huawei Device Co., Ltd. & https://www.vmall.com/ & vmall \\
\hline 26 & Kohl's Corporation & https://www.kohls.com/ & kohls \\
\hline 27 & Amazon EU S.à r.l. & https://www.amazon.es/ & amazon_Es \\
\hline 28 & W.W. Grainger, Inc. & https://www.grainger.com/ & grainger \\
\hline 29 & H \& M Hennes \& Mauritz GBC AB & https://www.hm.com & $\mathrm{hm}$ \\
\hline 30 & Sam's West, Inc. & https://www.samsclub.com/ & samsclub \\
\hline 31 & Amazon EU S.à r.l. & https://www.amazon.it/ & amazon It \\
\hline 32 & Otto GmbH \& Co. KG & https://www.otto.de/ & otto \\
\hline 33 & The Kroger, Co. & https://www.kroger.com/ & kroger \\
\hline 34 & HQG, Ltd. & https://www.kaola.com/ & kaola \\
\hline 35 & Zara USA, Inc. & https://www.zara.com/ & zara \\
\hline 36 & QVC, Inc. & https://www.qvc.com/ & qve \\
\hline 37 & Dell, Inc. & http://www1.la.dell.com/ & la \\
\hline 38 & Lowe's Home Centers, LLC & https://www.lowes.com/ & lowes \\
\hline 39 & asos.com, Ltd. & https://www.asos.com/ & asos \\
\hline 40 & Sainsbury's Supermarkets, Ltd. & https://www.sainsburys.co.uk/ & sainsburys \\
\hline 41 & Nordstrom, Inc. & https://www.nordstrom.com/ & nordstrom \\
\hline 42 & DSG Retail, Ltd. & https://www.currys.co.uk/ & currys \\
\hline 43 & Gap, Inc. & https://www.gap.com/ & gap \\
\hline 44 & MVM, OOO & https://www.mvideo.ru/ & mvideo \\
\hline 45 & Auchan Retail France SAS & https://www.auchan.fr/ & auchan \\
\hline 46 & ZoeTop Business Co., Ltd. & https://www.shein.com/ & shein \\
\hline 47 & John Lewis Plc & https://www.johnlewis.com/ & johnlewis \\
\hline 48 & Magazine Luiza S.A. & https://www.magazineluiza.com.br/ & magazineluiza \\
\hline 49 & Ocado Retail, Ltd. & https://accounts.ocado.com/ & ocado \\
\hline 50 & Newegg, Inc. & https://www.newegg.com/ & newegg \\
\hline
\end{tabular}




\section{Table 2 (on next page)}

Table 2 E-commerce websites evaluated.

It presents a sample of 50 e-commerce stores according to the ranking of the classification proposed by ecommerceDB, followed by the acronym, errors, contrast errors, alerts, features, structural elements, ARIA, and the country to which each e-commerce corresponds. 
1 Table 2 E-commerce websites evaluated. It presents a sample of 50 e-commerce stores according to the ranking of

2 the classification proposed by ecommerceDB, followed by the acronym, errors, contrast errors, alerts, features,

3 structural elements, ARIA, and the country to which each e-commerce corresponds.

\begin{tabular}{|c|c|c|c|c|c|c|c|c|}
\hline Ranking & Acronym & Errors & $\begin{array}{l}\text { Contrast } \\
\text { Errors }\end{array}$ & Alerts & Features & $\begin{array}{l}\text { Structural } \\
\text { Elements }\end{array}$ & ARIA & Country \\
\hline 1 & amazon_Us & 4 & 4 & 106 & 140 & 46 & 270 & United States \\
\hline 2 & global & 24 & 35 & 47 & 11 & 13 & 2 & Greater China \\
\hline 3 & apple & 10 & 21 & 17 & 24 & 61 & 122 & United States \\
\hline 4 & walmart & 1 & 6 & 72 & 104 & 20 & 321 & United States \\
\hline 5 & suning & 102 & 34 & 113 & 112 & 29 & 3 & Greater China \\
\hline 6 & amazon_De & 4 & 4 & 94 & 217 & 56 & 380 & Germany \\
\hline 7 & amazon_Uk & 8 & 2 & 97 & 189 & 56 & 387 & United Kingdom \\
\hline 8 & vip & 73 & 53 & 28 & 12 & 22 & 1 & Greater China \\
\hline 9 & target & 1 & 6 & 11 & 45 & 31 & 125 & United States \\
\hline 10 & amazon_Jp & 5 & 1 & 32 & 37 & 31 & 104 & Japan \\
\hline 11 & midea & 21 & 83 & 57 & 222 & 59 & 0 & Greater China \\
\hline 12 & homedepot & 26 & 40 & 93 & 86 & 108 & 247 & United States \\
\hline 13 & bestbuy & 6 & 0 & 4 & 19 & 19 & 2 & United States \\
\hline 14 & amazon_Ca & 6 & 1 & 142 & 218 & 56 & 572 & Canada \\
\hline 15 & wayfair & 41 & 0 & 14 & 66 & 279 & 329 & United States \\
\hline 16 & amazon_Fr & 4 & 2 & 95 & 210 & 53 & 464 & France \\
\hline 17 & costco ${ }^{-}$ & 16 & 7 & 131 & 220 & 135 & 1071 & United States \\
\hline 18 & chewy & 1 & 2 & 27 & 152 & 98 & 234 & United States \\
\hline 19 & nike & 2 & 0 & 105 & 93 & 28 & 76 & United States \\
\hline 20 & ikea & 1 & 6 & 6 & 18 & 18 & 120 & United States \\
\hline 21 & tesco & 9 & 4 & 47 & 24 & 131 & 165 & United Kingdom \\
\hline 22 & macys & 1 & 0 & 20 & 16 & 114 & 75 & United States \\
\hline 23 & $\operatorname{argos}$ & 15 & 2 & 23 & 14 & 28 & 195 & United Kingdom \\
\hline 24 & wildberries & 140 & 266 & 175 & 145 & 134 & 36 & Russia \\
\hline 25 & vmall & 107 & 27 & 29 & 26 & 47 & 0 & Greater China \\
\hline 26 & kohls & 38 & 9 & 287 & 151 & 25 & 894 & United States \\
\hline 27 & amazon_Es & 4 & 2 & 111 & 205 & 60 & 404 & Spain \\
\hline 28 & grainger & 9 & 7 & 34 & 39 & 86 & 102 & United States \\
\hline 29 & $\mathrm{hm}$ & 1 & 1 & 1 & 1 & 19 & 0 & Germany \\
\hline 30 & samsclub & 12 & 0 & 86 & 111 & 119 & 1173 & United States \\
\hline 31 & amazon_It & 5 & 2 & 81 & 208 & 58 & 410 & Italy \\
\hline 32 & otto & 43 & 155 & 77 & 62 & 76 & 0 & Germany \\
\hline 33 & kroger & 2 & 10 & 50 & 39 & 44 & 221 & United States \\
\hline 34 & kaola & 60 & 246 & 772 & 246 & 259 & 2 & Greater China \\
\hline 35 & zara & 7 & 0 & 13 & 10 & 20 & 286 & United States \\
\hline 36 & qve & 2 & 4 & 262 & 192 & 185 & 392 & United States \\
\hline 37 & la & 2 & 38 & 38 & 23 & 163 & 2 & United States \\
\hline 38 & lowes & 8 & 4 & 27 & 20 & 31 & 232 & United States \\
\hline 39 & asos & 24 & 3 & 0 & 66 & 169 & 366 & United Kingdom \\
\hline 40 & sainsburys & 0 & 6 & 26 & 53 & 47 & 47 & United Kingdom \\
\hline 41 & nordstrom & 57 & 6 & 36 & 11 & 236 & 49 & United States \\
\hline 42 & currys & 51 & 6 & 46 & 58 & 82 & 62 & United Kingdom \\
\hline 43 & gap & 11 & 1 & 23 & 45 & 33 & 195 & United States \\
\hline
\end{tabular}




\begin{tabular}{llccccccl}
\hline 44 & mvideo & 63 & 217 & 98 & 202 & 131 & 2 & Russia \\
45 & auchan & 37 & 233 & 38 & 61 & 82 & 57 & France \\
46 & shein & 127 & 33 & 118 & 72 & 161 & 618 & United States \\
47 & johnlewis & 6 & 17 & 40 & 27 & 47 & 39 & United Kingdom \\
48 & magazineluiza & 39 & 196 & 232 & 14 & 153 & 111 & Brazil \\
49 & ocado & 4 & 2 & 2 & 0 & 5 & 6 & United Kingdom \\
50 & newegg & 7 & 0 & 192 & 97 & 667 & 367 & United States \\
\hline
\end{tabular}

4 


\section{Table 3 (on next page)}

Table 3 Summary of the evaluation of e-commerce websites.

Shows the summary of accessibility barriers identified by applying the WAVE automatic review tool. 
1 Table 3 Summary of the evaluation of e-commerce websites. Shows the summary of accessibility barriers identified 2 by applying the WAVE automatic review tool.

\begin{tabular}{llllr}
\hline Barrier & $\begin{array}{l}\text { Success } \\
\text { criteria }\end{array}$ & Level & Principle & Total \\
\hline Non-text Content & 1.1 .1 & $\mathrm{~A}$ & Perceivable & 774 \\
Info and Relationships & 1.3 .1 & $\mathrm{~A}$ & Perceivable & 94 \\
Contrast (Minimum) & 1.4 .3 & $\mathrm{AA}$ & Perceivable & 1641 \\
Keyboard & 2.1 .1 & $\mathrm{~A}$ & Operable & 8 \\
Bypass Blocks & 2.4 .1 & $\mathrm{~A}$ & Operable & 12 \\
Link Purpose (In Context) & 2.4 .4 & $\mathrm{~A}$ & Operable & 350 \\
Headings and Labels & 2.4 .6 & $\mathrm{AA}$ & Operable & 44 \\
Language of Page & 3.1 .1 & $\mathrm{~A}$ & Understandable & 8 \\
Error Identification & 3.3 .1 & $\mathrm{~A}$ & Understandable & 2 \\
Labels or Instructions & 3.3 .2 & $\mathrm{~A}$ & Understandable & 35 \\
Name, Role, Value & 4.1 .2 & $\mathrm{~A}$ & Robust & 51 \\
\hline
\end{tabular}

3

4 


\section{Table 4 (on next page)}

Table 4 Normality tests.

Show normality tests for Lilliefors significance correction. We applied for errors, contrast errors, and ranking. 
1

2 Table 4 Normality tests. Show normality tests for Lilliefors significance correction. We applied for errors, contrast 3 errors, and ranking.

\begin{tabular}{|c|c|c|c|c|}
\hline \multicolumn{5}{|c|}{ Kolmogorov-Smirnov one-sample test } \\
\hline & & Errors & $\begin{array}{l}\text { Contrast } \\
\text { Errors }\end{array}$ & Ranking \\
\hline$\overline{\mathrm{N}}$ & & 50 & 50 & 50 \\
\hline \multirow{2}{*}{$\begin{array}{l}\text { Normal } \\
\text { parameters a,b }\end{array}$} & Media & 24.94 & 36.08 & 25.50 \\
\hline & $\begin{array}{l}\text { Standard } \\
\text { deviation }\end{array}$ & 34.064 & 71.184 & 14.577 \\
\hline \multirow{3}{*}{$\begin{array}{l}\text { Maximum } \\
\text { extreme } \\
\text { differences }\end{array}$} & Absoluto & 0.248 & 0.323 & 0.065 \\
\hline & Positivo & 0.248 & 0.323 & 0.065 \\
\hline & Negativo & -0.232 & -0.306 & -0.065 \\
\hline \multicolumn{2}{|c|}{ Test statistic $=\mathrm{p}$} & 0.248 & 0.323 & 0.065 \\
\hline \multicolumn{2}{|c|}{$\begin{array}{l}\text { Asymptotic significance } \\
\text { (bilateral) }\end{array}$} & $0.000^{\mathrm{c}}$ & $0.000^{\mathrm{c}}$ & $0.200^{\mathrm{c}, \mathrm{d}}$ \\
\hline
\end{tabular}

4

$5 \mathrm{a}=$ The test distribution is normal. $\mathrm{b}=\mathrm{It}$ is calculated from data. $\mathrm{c}=$ Lilliefors significance correction. $\mathrm{d}=$ This is a lower 6 limit of true significance.

7 


\section{Table 5 (on next page)}

Table 5 Spearman correlation.

It shows Spearman's non-parametric correlation between the ranking of e-commerce websites and accessibility barriers. Spearman's Rho correlation is 0.329 , indicating that the correlation is low positive. 
1 Table 5 Spearman correlation. It shows Spearman's non-parametric correlation between the ranking of e-commerce 2 websites and accessibility barriers. Spearman's Rho correlation is 0.329 , indicating that the correlation is low positive.

\begin{tabular}{lllrr}
\hline & & & Ranking & \multicolumn{1}{c}{ Errors } \\
\hline Spearman's & Ranking & Correlation & 1 & 0.141 \\
Rho & & coefficient & & \\
& & Sig. (bilateral) & 50 & 0.329 \\
& N & 0.141 & 50 \\
& \multirow{2}{*}{ Errors } & Correlation & & 1 \\
& & coefficient & 0.329 & \\
& & Sig. (bilateral) & 50 & 50 \\
\hline
\end{tabular}

3 